\title{
TITLE:
}

\section{EVIDENCE FOR THE VALIDITY OF MATSUMOTO'S CLASSIFICATION OF THE OPHIUROIDEA}

$\operatorname{AUTHOR}(S)$ :

Fell, H. Barraclough

\section{CITATION:}

Fell, H. Barraclough. EVIDENCE FOR THE VALIDITY OF MATSUMOTO'S CLASSIFICATION OF THE OPHIUROIDEA. PUBLICATIONS OF THE SETO MARINE BIOLOGICAL LABORATORY 1962, 10(2): 145-152

ISSUE DATE:

1962-12-31

URL:

http://hdl.handle.net/2433/175315

RIGHT: 


\title{
EVIDENCE FOR THE VALIDITY OF MATSUMOTO'S CLASSIFICATION OF THE OPHIUROIDEA
}

\author{
H. Barraclough FELL \\ Victoria University of Wellington \\ Wellington, New Zealand
}

With 3 Text-figures

\begin{abstract}
New anatomical evidence derived from study of the endoskeleton and of the soft parts in the recently recognized surviving somasteroid Platasterias, and the surviving oegophiurid Ophiocanops, discloses the archaic nature of the ophiuroids classified in the families Asteronychidae, Asteroschematidae, Euryalidae and Ophiomyxidae. These families all fall within the Phrynophiurida, as defined by MATSUMOTo (1915), considered by him to be related to fossil forms, and the most generalised existing ophiuroids. MATsumoto's classification accordingly receives strong support, and must be accepted.
\end{abstract}

In 1915 Professor Hikoshichiro Mатsumoto published a revolutionary classification of the Ophiuroidea, which he subsequently elaborated in a longer contribution in 1917. He abandoned the time-honoured division of the group into Euryalae and Ophiurae, proposing instead a new arrangement, in which were recognized a fossil group named Oegophiuroida, and four extant groups (regarded as orders). The former was defined on the general characters of the skeleton, the latter on the basis mainly of the structure and relations of the radial shields and genital plates. Matsumoto's classification has received the consistent support of H. L. C Cark, R. Koehler and S. Murakami. On the other hand it was rejected by Th. Mortensen, A. M. Djakonov, L. Döderlein, H. B. Fell and other writers, for various reasons. The main criticism came from Th. MoRTENSEN (1927) who wrote: "Another, more recent classification, proposed by Matsumoto, is mainly founded on differences in the shape of the first vertebrae and the articulation of the genital plate with the radial shield; it divides the Ophiurans into the following orders: Phrynophiurae*, Laemophiurae, Gnathophiurae, and Chilophiurae. The present author cannot acept this classification; especially the Phrynophiuridae* seem a very artificial group, containing both the Ophiomyxidae

* These inconsistencies in terminations are due to MORTENSEN, and are quoted as written by him. Matsumoto himself used the ordinal terminations in-ida.

Publ. Seto Mar. Biol. Lab., X (2), 1962. (Article 9) 
and the Euryalids. The Ophiomyxidae may well be regarded as the most primitive of the Zygophiurids, but they are probably not nearly related to the Euryalids, with quite a different type of vertebrae." MoRTensen adopted the older classification into Euryalae (Euryalina) and Ophiurae (Ophiurina), basing the two-fold division upon the structure of the vertebrae and the nature of the articulations between them, and this course was also followed by the other authors cited as differing from Matsumoto. There has been no agreement as to which of the groups Ophiurina and Euryalina might be the more primitive, and Mortensen himself gave no opinion, though he listed Euryalina first. I have followed Mortensen's arrangement in all my own papers until now. Recently, as a totally unforeseen outcome of comparative morphological studies, living representatives of several supposedly extinct groups of Asterozoa have become known, including a somasteroid (FelL, 1961, 1962a, 1962 b, 1962 c), Platyasterida (1962d, and papers in press), and-most important in the present context-an oegophiurid (1962d, and in press). The two first of these finds implied that archaic asterozoans must have possessed a pinnate skeletal structure, slmilar to that of pinnulate crinoids. As the surviving platyasterids (Luidiidae) indicated that the modern asteroid skeleton had been derived from the pinnate skeleton of somasteroids (FELL, $1962 \mathrm{~b}$ ), it followed that if ophiuroids had also been derived from somasteroids (as suspected), they too must once have possessed a pinnate skeleton. A series of dissections soon demonstrated that such pinnate structure still persists in certain living ophiuroids (FELL, in press), all of which belong in Euryaline families. Fossil ophiuroids are also known with pinnate endoskeletal structure. These data indicated an archaic aspect of euryaline anatomy. Further, Matsumoto had himself discovered that in some euryaline genera the gonads are not restricted to the disc, but send extensions into the arms. Mortensen (1932, 1933) also demonstrated euryaline structure of the same kind, and discovered that in the supposed ophiomyxid Ophiocanops the gonads are arranged in paired serial sequence in the arms. He also found that in Ophiocanops the stomach sends a long caecum into each arm. On the basis of these observations, Mortensen erected the family Ophiocanopidae to accommodate Ophiocanops, which, on account of similarities to the Ophiomyxidae, was regarded as referable to the Ophiurina.

Matters thus rested until this year. Then, in the light of evidence supplied by the surviving somasteroid and platyasterids, it became obvious to me that Ophiocanops, far from being a very specialised ophiuroid (as MorTensen had inferred), must in reality be a very archaic form; for the somasteroid and platyasterids showed that archaic asterozoans possessed serial brachial gonads, and a caecum of the stamach extending into the arm. Accordingly I addressed a request to Dr. F. J. MADSEN of the Copenhagen Zoological Museum for permission to dissect the endoskeleton of a specimen of Ophiocanops, indicating the grounds for suspecting its archaic nature. As now recorded in a paper still in press, the 
dissection confirmed the inference, for it showed that Ophiocanops is really a member of the supposedly extinct Oegophiurida, and that the characters of the family Ophiocanopidae must really be the soft-part characters of that order, previously known only from the hard structures preserved as Palaeozoic fossils.

These results, though of great intrinsic interest, have an important bearing upon Matsumoto's classification. The characters of Ophiocanops clearly link it with the Ophiomyxidae, as recognized by Koenler (1922) and Mortensen (1932), but at the same time other characters link it with the Euryalina, as also recognised by Mortensen (1932). It will be seen, therefore, that the conventional classification of the Ophiuroidea, in which the Euryalina are separated from the Ophiocanopidae and Ophiomyxidae, the two latter being united with the Ophiurae, is completely at variance with the results now obtained. On the other hand, MAtsumoto's interpretation, by which the Ophiomyxidae would be linked with the Euryalina, in one group, the Phrynophiurida, is perfectly adapted to express the relationship now inferred; also, the disposition of Ophiocanops as a member of the Oegophiurida, has a bearing upon Matsumoto's views, for he regarded the Ophiomyxidae as archaic forms, and it is plain that this also follows from the present study, since the nearest relationships of the Ophiomyxidae would be with the Ophiocanopidae.

It will be seen thus, that a completely independent source of evidence has become available, and that the evidence yielded by it agrees with that provided by Matsumoto's own studies. Further, when I communicated my result to my friend Dr. Shiro Murakami, he was kind enough as to place in my hands his own unpublished research on the oral and dental plates of ophiuroids, from which it is clear that this third line of evidence adds yet more support to the views first promulgated by Matsumoto. Accordingly, I gladly acknowledge the overwhelming superiority of internal structure, especially that of the endoskeleton, over the superficial characters of the external surface of the body, as a means of recognizing the real affinities of Ophiuroidea. As also evident in my own recent publications on somasteroids and asteroids, the endoskeleton here, too, proved the essential guide to the natural affinities of extant and fossil asterozoans.

In view of these facts, I think it will be admitted that the Phrynophiurida are a natural grouping, falling after the Oegophiurida, and before the Ophiurida. The simplest means of introducing it into the general classification is to maintain it as an order, as Matsumoto himself intended. Owing to discoveries made since Matsumoto's day, it is no longer justifiable to keep Ophiuroidea apart from other asterozoans as a distinct class. Consequently, some of the other groupings proposed by Матsuмото (1915), as of ordinal status, would be more conveniently considered as suborders of Ophiurida. I therefore venture to propose the following arrangement of the taxa as meeting all the requirements of the evidence now in our hands : 


\section{Subphylum Asterozoa \\ Class Stelleroidea}

\section{Subclass 1: Somasteroidea}

Content as defined by FELL (in Phylogeny of Sea-stars)

Subclass 2: Asteroidea

Content as defined by FELL (ibid.)

\section{Subclass 3: Ophiuroidea}

Order 1: Stenurida Spencer (Content as defined by Spencer, 1951)

Order 2: Oegophiurida Matsumoto (Content as defined by Fell ibid.)

Order 3: Phrynophiurida Matsumoto

Suborder Ophiomyxina nov.

Content: Family Ophiomyxidae: The characters of the suborder being those of the family.

Suborder Euryalina $M$ \& $T$.

Content as defined by FeLL, 1960.

Order 4: Ophiurida M \& T (Syn. Myophiuroida Matsumoto, 1915)

Comprising all other ophiuroid groups. The exact manner in which the various families are to be arranged will depend upon the stress placed on particular characters : since, however MATsumoto's conclusions receive strong support by Murakami (1947, and unpublished data), and in the case of the Phrynophiurida are also supported by FELL (herein), it may well be that the eventual outcome of uncompleted studies will be the complete adoption of Matsumoto's original proposals.

Whilst it is not necessary to review here all the evidence already submitted in the two papers listed in the references as in press at the time of writing, a few of the more relevant data are illustrated in the figures herewith. Figure 1 shows the diagnostic features of the arm-sdeleton, as seen in sections of the arm in the fossil orders of ophiuroids. It will be noted that Matsumoto, and all subsequent writers (including myself as late as 1961) interpreted the oegophiurid skeleton as implying an open ambulacral groove (labelled 4 in Figure 1). This, it is now seen, is a misinterpretation. The groove was, in fact, already closed by muscular integument in oegophiurids. The fossils were correctly interpreted as indicating that no bursa had evolved, for Ophiocanops (Figures 2 and 3) has none, and the gonads lie in the arm. Like the fossils, Ophiocanops has no oral shields, no genital plates, no dorsal and ventral arm-plates, and the madreporite lies at the edge of the disc. All these features are illustrated in the figures, and require no further comment here. 


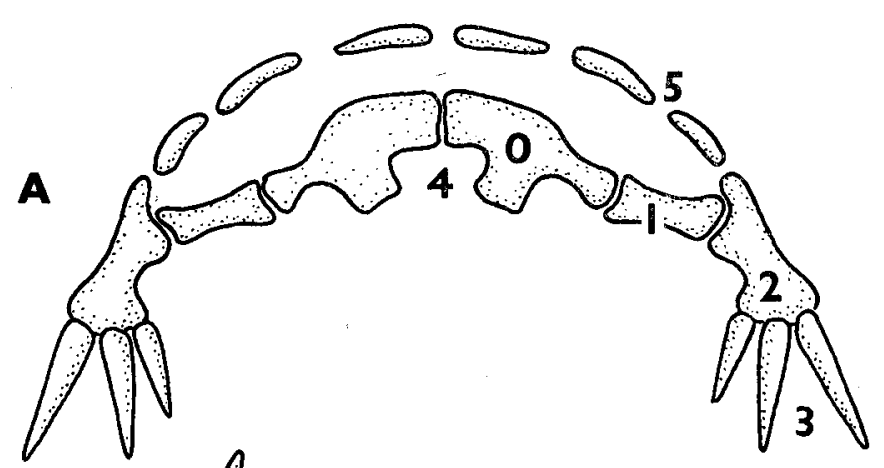

B
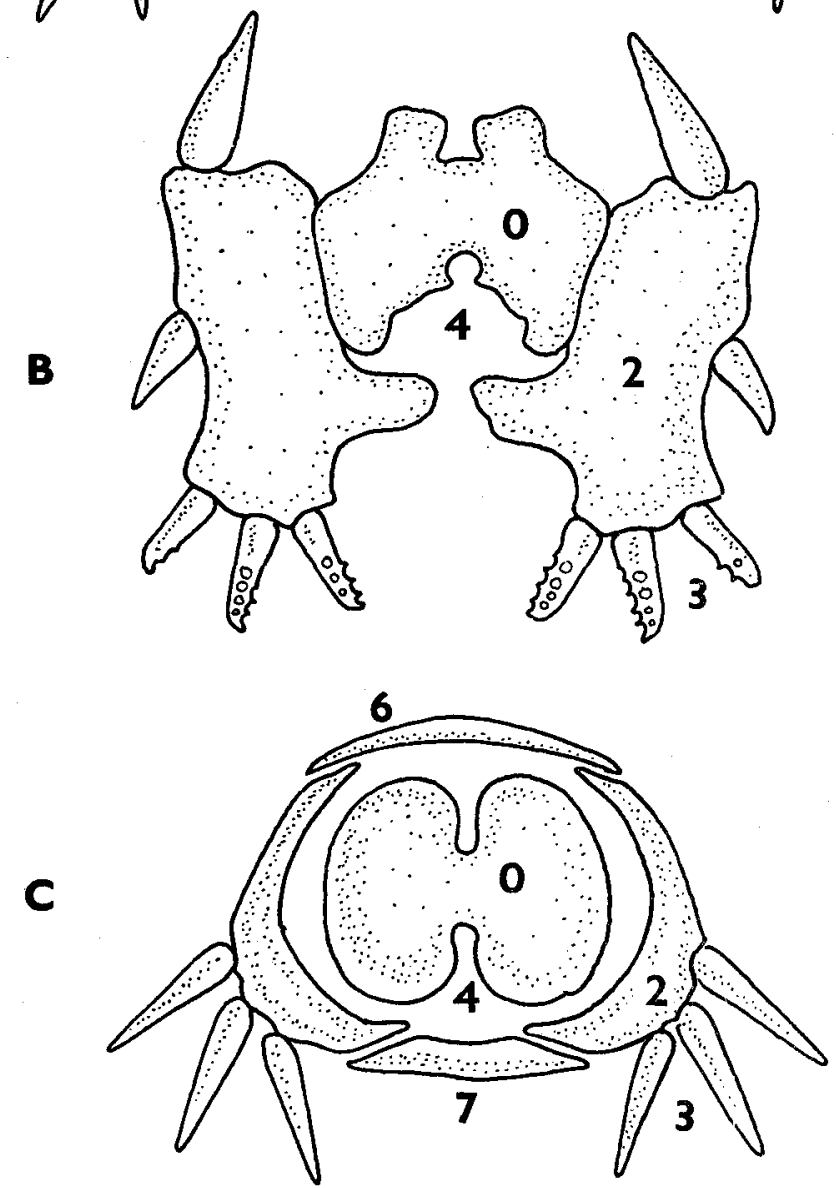

Figure 1. Cross-sections of the arm in ophiuroids, to show evolution of the skeleton. A, Order Stenurida (Lower Palaeozoic). B, Order Oegophiurida (Lower Palaeozoic to Recent). C, Ophiurida (Upper Palaeozoic to Recent). Abbreviations : $\mathrm{O}$, ambulacral element; 1 , first virgalium (sublateral plate, V-1);2, second virgalium (lateral plate, V-2) 3 , spines of $\mathrm{V}-2 ; 4$, subambulacral groove; 5 , aboral plates of somasteroid derivation; 6 , aboral plate (dorsal arm-plate) of secondary derivation; 7 , ventral arm-plate, of secondary derivation. 

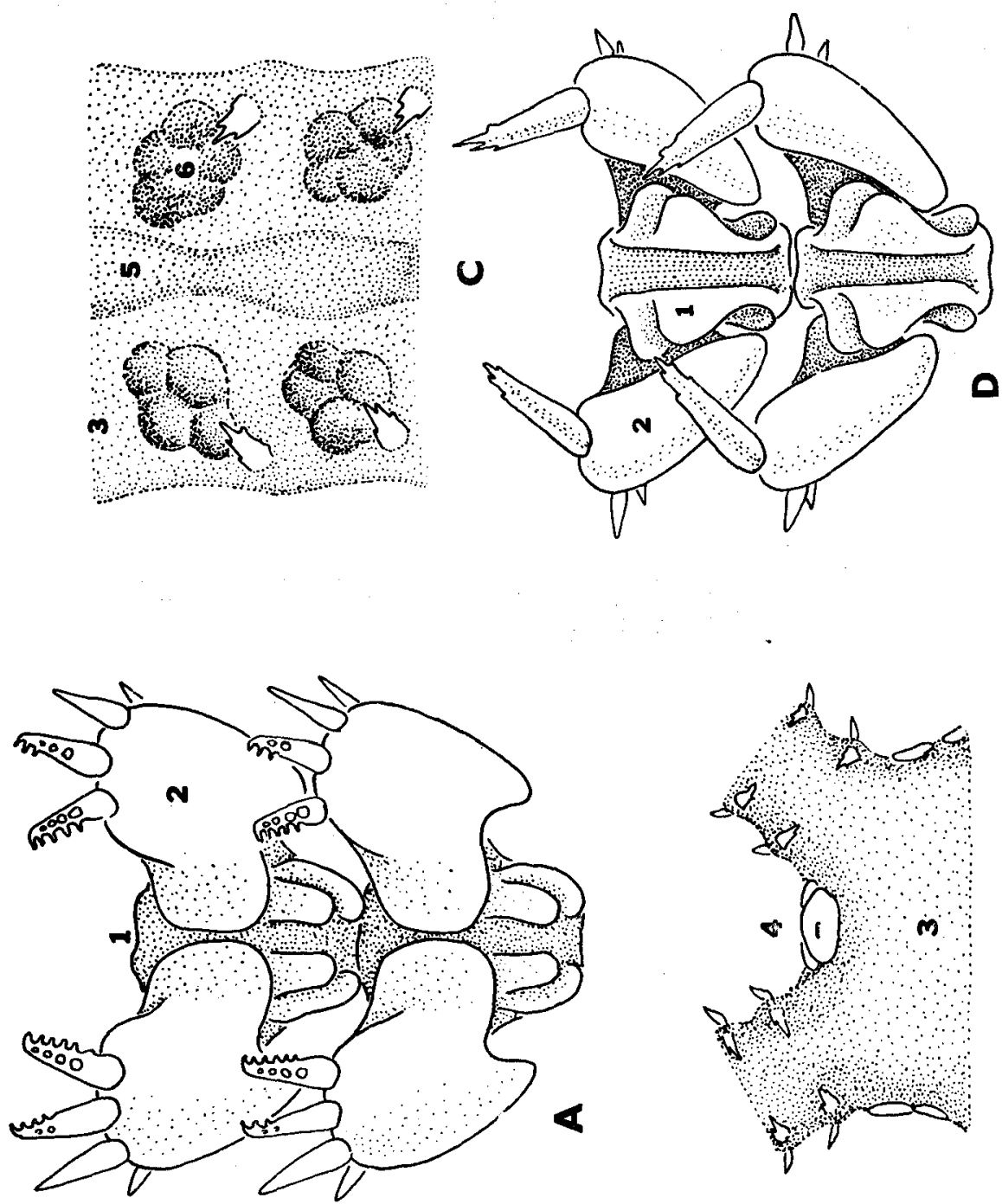

Figure 2. Characters of Ophiocanops fugiens (Family Ophiocanopidae, Order Oegophiurida). $A$, skeleton in ventral dissection. $B$, dorsal aspect of disc, showing lateral madreporite. $C$, dorsal aspect of arm, entire, but rendered translucent by detergent treatment, showing caecum and gonads. D, skeleton in dorsal dissection, after removal of gonads and caecum. Abbreviations : 1 , vertebra; 2 , lateral plate; 3 , dorsal body-wall of naked integument; 4 , madreporite; 5 , caecum ; 6 , gonad. 

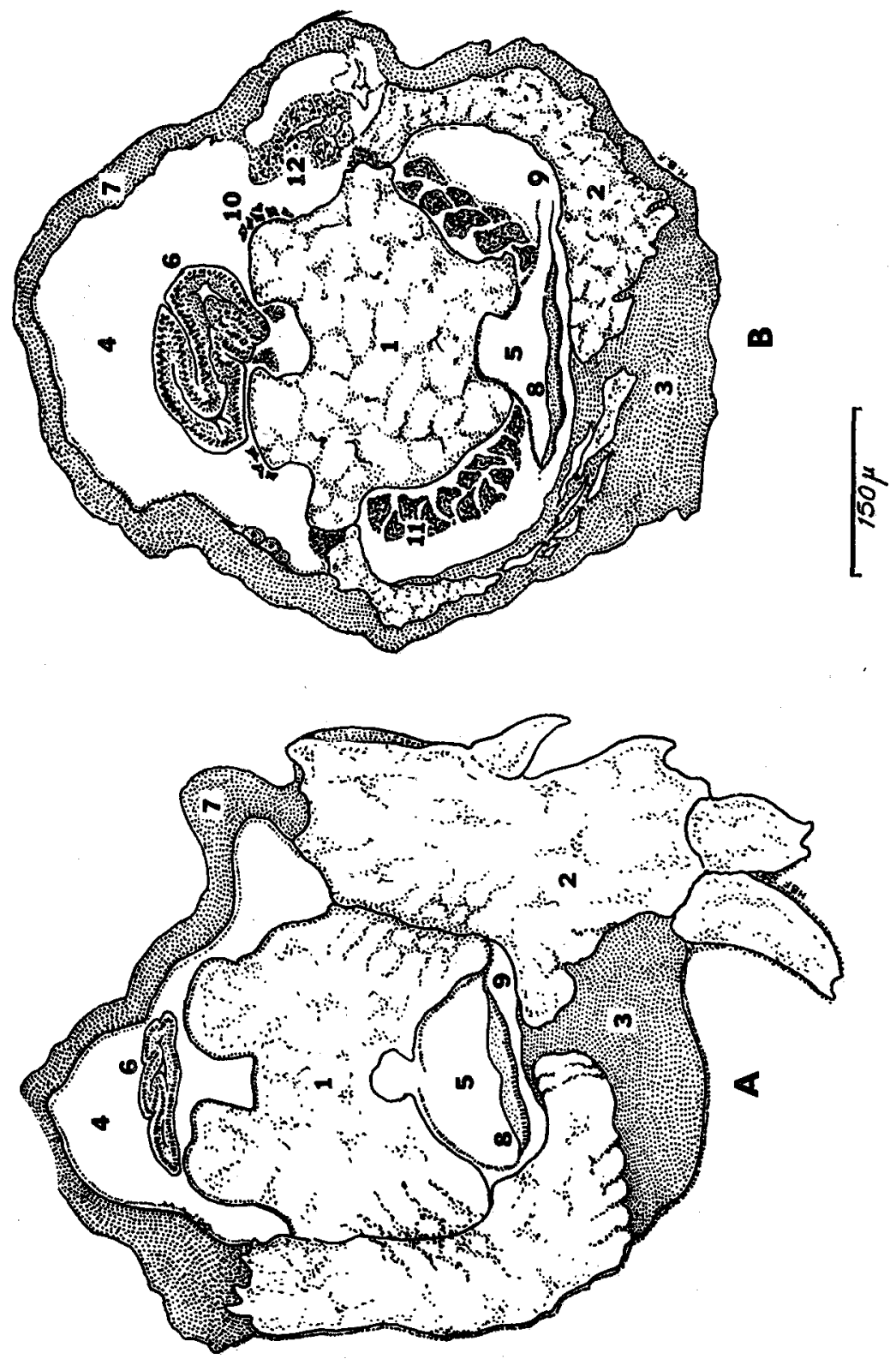

Figure 3. Ophiocanops fugiens (Family Ophiocanopidae, Order Oegophiurida). A, obliquely transverse section of arm, cut through distal part of a segment. B, obliquely transverse section of arm, cut through proximal part of a segment. Abbreviations : 1, vertebra; 2, lateral plate; 3 , ventral muscle ; 4 , dorsal coelom; 5 , subambulacral coelom; 6 , caecum; 7 , dorsal integument ; 8, radial nerve; 9 , hyponeural canal, the homologue of the radial groove of somasteroids, and of epineural canal of echinozoans; 10, dorsolateral muscles; 11 , ventrolateral muscles; 12, gonad (ovary), with part of oviduct visible to right. 
Acknowledgments: I beg to acknowledge the generous cooperation of Dr. F. Jensenius MADSEN, Copenhagen Zoological Museum, in supplying material of Ophiocanops.

I also wish to express to Dr. A. G. CLARK, of Napier, my appreciation of his invaluable assistence in cutting microtome sections of the extremely refractory material. The material was originally collected by the late Dr. Th. Mortensen in Jolo, Indonesia, in 1929; it was apparently dried (ex alcohol) in about 1932. Thirty years later the material was reconstituted in aqueous trisodium phosphate, and then decalcified with sodium hexametaphosphate. Sectioning, when undertaken by Dr. A. G. $C_{\text {LARK, }}$, proved unusually difficult, as the material was of course very brittle, even when double embedded in celloidin and paraffin. In most sections the internal structures fell out; but eventually, by cutting thick sections (at 10 microns), and coating each section on the slide with celloidin, some successful series were obtained. This technique forbade any very refined staining methods, and virtually necessitated using Heidenhain's haematoxylin and eosin; even this staining did not take ideally, owing to the poor fixation of the original material. However, the general histology was distinctly demonstrated, and the interpretation was aided by the prior dissection of other parts of the arm, and by comparison of the structures with those seen in other phrynophiurid ophiuroids. In particular, the disposition of the skeletal elements was clearly demonstrated in both sections and dissections, and these structures were the critical ones which had been omitted from Mortensen's (1932) account.

May I conclude this note by paying tribute to the perspicacity of Professor Hikoshichiro Matsumoto, whose researches and inductions would now appear to have been far in advance of his own age, and constitute a monumental contribution of Japanese scholarship. Also I would acknowledge the prime importance of the late Dr. Theodor Mortensen's observation on the presence of the caecum and gonads in the arm of Ophiocanops, a discovery which eventually led to the recognition of that ophiuroid as a surviving oegophiurid.

\section{REFERENCES}

FelL, H. Barraclough 1961. (cited in) The Times (London), 55, 270 (Dec. 21), p. 8. 1962a. Science, 136, 633-636.

1962b. Univ. Kansas Pal. Contrib., Echinodermata, 6.

1962c. Zoologicheski Zhurnal (Akad. Nauk CCCP), 41 (9).

1962d. Tuatara, 10 (3).

(in press) Phylogeny of Sea-Stars. Phil. Trans., Ser. B.

(in press) Phylogeny of the Echinoderms, Ann. Rpt. Smithson. Inst., 1962.

KOEHLER, Rene 1922. Bull. U.S. Nat. Mus., 100 (5).

Matsumoto, Hikoshichiro 1915. Proc. Acad. Nat. Sci. Philad., 47, 43. 1917. J. Coll. Sci. Imp. Univ. Tokyo, 38, 2.

Mortensen, Theodor 1927. Echinoderms of the British Isles (Oxford). 1932. Vid. Medd. Dansk. naturh. For., 93. 1933. ibid., 96 .

Murakami, S. 1947. A study on the dental and oral phates of the Ophiuroidea. Seibutu, 2 (4), 97-104, figs. 1-2. (In Japanese.) 